\title{
Characterizing Rhizodegradation of the Insecticide Bifenthrin in Two Soil Types
}

\author{
Xuan Le, Dafeng Hui, Emmanuel Kudjo Dzantor* \\ College of Agriculture, Human and Natural Sciences, Tennessee State University, Nashville, USA. \\ E-mail: *edzantor@tnstate.edu \\ Received May 24 $4^{\text {th }}, 2011$; revised July $8^{\text {th }}, 2011$; accepted August $19^{\text {th }}, 2011$.
}

\begin{abstract}
Rhizodegradation is a process by which plant-supplied substrates stimulate microbial populations in plant root zones (rhizospheres) to cause removal of undesirable levels of contaminants in soil. This study characterized rhizodegradation of the insecticide bifenthrin in Armour silt loam and Sullivan fine sandy loam soils that were planted with switchgrass, big bluestem, and alfalfa. After six weeks in soils, plate dilution frequency assays (PDFA) of bacterial populations were higher in all planted soils than in unplanted ones. Planted Sullivan soils contained higher bacteria than corresponding Armour soils and alfalfa rhizospheres of both soil types contained highest bacteria. Bacterial populations generally increased between week 6 and week 10, before declining in each treatment at week 12. Carbon utilization patterns (CUP) of bacterial communities, measured as color development on BIOLOG plates, were higher in planted soils than in unplanted ones. Principal Component Analysis (PCA) constructed patterns based on different extents of color development; these patterns were used to relate microbial communities in the different treatments. Gas chromatography $(G C-E C D)$ showed that significantly more bifenthrin dissipated in planted soils than unplanted ones. Different levels of bifenthrin were recovered in planted soils but the differences were generally not significant. Data are being evaluated further to provide a basis for the development of strategies for enhancing rhizodegradation of soils contaminated with bifenthrin.
\end{abstract}

Keywords: Rhizodegradation, Microbial Community, Substrate Utilization Patters, Biolog, Bifenthrin, Pesticide Dissipation

\section{Introduction}

Soil contamination with xenobiotic contaminants including pesticides poses great threats to human and ecosystem health. Phytoremediation is currently recognized as the one of the most cost-effective and appealing approaches for cleaning up soils contaminated with a broad range of xenobiotic chemicals. The appeal of phytoremediation derives from its applicability across a broad range of environmental matrices and types of contaminants when the appropriate plant and plant systems are used. Thus, phytoremediation strategies have been used or explored for remediating or mitigating soils, sediments and water contaminated with inorganic substances including toxic metals [1] nutrients [2] and propellants [3] as well organic contaminants such as polyaromatic hydrocarbons [4] nitroaromatic compounds [5] polychlorinated biphenyls [6] and pesticides [7] An aspect of phytoremediation of organic contaminants is rhizodegradation, a process in which plant-supplied substrates stimulate mi- crobial communities in plant root zones (rhizospheres) to cause contaminant dissipation.

In spite of great interest and study, aspects of rhizodegradation have remained inadequately understood, much the same way as many rhizosphere phenomena, thereby delaying its routine implementation for cleaning up specific soil contaminants. For example, its applicability is limited for highly lipophilic compound such as bifenthrin [8] an important insecticide used in the nursery industry for quarantine treatment of Japanese beetles and imported fire ants [9]. Bifenthrin is a pyrethroid insecticide that belongs in the family of a new generation chemistries that are notable for their high efficacies at relatively low applications [10]. In spite of this desirable attribute, bifenthrin and related compounds are quite persistent in soil; accordingly, potentials exist for their accumulation in soil and consequently, potentials for their intrusions into vulnerable ecosystems. It is important to explore strategies for enhancing rhizodegradation of lipophilic compounds. Such materials are not subjected to the other 
major phytoremediation processes of uptake and translocation into plant tissues where they could be metabolized.

The purpose of this study is to understand and characterize the microbial components involved in the dissipation of bifenthrin in soils to provide a basis for strategies that may be used to mitigate its undesirable intrusions in soil and potentially water.

\section{Materials and Methods}

\subsection{Materials}

\subsubsection{Soils}

The two soil types used in this study were Armour silt loam (fine-silty, mixed, thermic Ultic Hapludalfs, and Sullivan fine sandy loam (fine-loamy siliceous, active, thermic Dystric Flaventic Eutrudets). Armour silt loam was collected from Tennessee State University Agricultural Experimental Station in Nashville, TN, and Sullivan sandy loam was collected from Tennessee Technological University Experimental Station in Cookeville, TN. They are heretofore designated as Armour and Sullivan soils respectively. Characteristics of both soils are presented in Table 1. Surface soils were collected, sieved through 2-mm sieve and stored in a refrigerator at $4^{\circ} \mathrm{C}$ until used.

\subsubsection{Crops}

Two grasses and one legume were selected for these investigations. The grasses were switchgrass (Panicum virgatum L.) and big bluestem (Andropogon gerardii Vitman), and the legume was alfalfa (Medicago sativa L.). They were among crops that our laboratory has previously investigated for phytoremediation of soils contaminated with dursban, flagships and chlordane (11). Seeds of Alamo variety of switchgrass and Roundtree variety of big bluestem were obtained from Star Seed Inc., Osborne, KS and seeds of Savannah variety of alfalfa were provided by the USDA Germplasm Research Information Network, Beltsville, MD. The plants were hereafter designated as AL (alfalfa), BB (big bluestem) and SG (switchgrass).

\subsubsection{Pesticide}

Bifenthrin was tested as a $7.9 \%$ a.i. emulsifiable concentrate distributed as Talstar ${ }^{\circledR}$ by FMC Corp. Standard so-

Table 1. Characteristics of armour and sullivan soils.

\begin{tabular}{lcc}
\hline Property & $\begin{array}{c}\text { Armour } \\
\text { silt loam }\end{array}$ & $\begin{array}{l}\text { Sullivan } \\
\text { sandy loam }\end{array}$ \\
\hline Sand (\%) & 40 & 49 \\
Silt (\%) & 15 & 16 \\
Clay (\%) & 45 & 35 \\
Org. Matter M (\%) & 2.1 & 1.2 \\
pH & 5.89 & 5.25 \\
\hline
\end{tabular}

lution of bifenthrin in methanol and neat compound(98\% purity) were obtained from ChemService, West Chester, PA. These materials were used as external standard for determining concentration of the insecticide at any time during incubation in soil, and to prepare stock solution for determining extraction efficiency of bifenthrin from the soils, respectively.

\subsection{Experimental Approaches}

\subsubsection{Soil Fortification}

Soils were fortified with Talstar to produce a nominal bifenthrin concentration of $10 \mathrm{mg} \cdot \mathrm{kg}^{-1}$. Fortified soils were sieved at least twice and they stored in the refrigerator at $4^{\circ} \mathrm{C}$ until used.

\subsubsection{Moisture Replacement Plant Growth System (Microcosm)}

Plants were grown in Moisture Replacement System (MRS) described by Dzantor and Woolston [12]. Essentially, each MRS unit consists of polyfoam-insulated box that is divided into two halves. The upper half is drilled with holes that fit snugly $50 \mathrm{~mL}$ conical tubes, which held soil. The lower half serves as reservoir for water and nutrients. Wicks were inserted through the bottom of the tubes such that they protrude about a third way into soil while the rest extends into the reservoir. The reservoir has a working volume of about nine liters ( $9 \mathrm{~L})$ and when the system is in operation, the wicks supply water and nutrients via hydraulic gradient to the soil.

\subsubsection{Plant Harvesting}

At intervals of 4, 6, 10, and 12 weeks, unplanted and rhizosphere soils were sampled for chemical and microbiological analyses. During harvesting, entire contents of conical tubes were removed and the shoots of the plants were severed at the soil surface. At this stage of growth, all the belowground parts of the microcosm were considered to be rhizosphere material. This material was macerated and mixed thoroughly using flamed utensils and procedures to avoid cross contamination of samples by microbes or chemical residues. Portions of the samples were placed in sterile Whil-Pak ${ }^{\circledR}$ bags (VWR Scientific, Suwannee, GA) and stored in the refrigerator at $4^{\circ} \mathrm{C}$ for more than 48 hours before they were analyzed for microbiological parameters. The remaining portions of rhizosphere soils were stored at $-30^{\circ} \mathrm{C}$ until analyzed for bifenthrin concentrations.

\subsection{Analytical Approaches}

\subsubsection{Microbiological Analysis}

Soil bacterial populations were characterized using the Plate Dilution Frequency Assay (PDFA) described by Harris and Sommers [13]. The PDFA technique involved plating eight replicates each of serial dilution at six levels 
onto appropriately marked agar plates. After incubation, total number of positive spots on the marked plates is recorded and referenced to statistical tables to provide estimates the most probable number of bacteria in soil.

For profiling microbial communities, 150 microliters of suspension from a selected dilution from the PDFA procedure $\left(10^{-2}\right)$ were plated into 96-well BIOLOG EcoPlates (Biolog Inc., Hayward CA). The plates contain 31 carbon substrates that are replicated three times on each plate with 3 control wells containing water. Each well contains a colorless respiration indicator, tetrazolium chloride, which turns purple with respiratory activity in the wells, with the intensity of color development a measure of extent to which a particular substrate is utilized. For qualitative analyses, individual substrates on the Biolog plate were grouped into categories as follows (number substrates/per category in parentheses): carbohydrates (7), amino acids (6), carboxylic acids (10), polymers (4) esters (3) and amines (2). Average well color development at $590 \mathrm{~nm}\left(\mathrm{~A}_{590}\right)$ of each category was plotted against duration of incubation to provide a graphical comparison into substrate utilization under the influences of different rhizospheres.

\subsubsection{Chemical Analyses}

Bifenthrin residues were extracted from soil with ethyl acetate using a rotary shaker protocol as described previously for PCB contaminated soils except extracts were not subjected to sulfuric acid cleanup [12]. The extracts were analyzed by electron capture gas chromatography using an Agilent 6890 system with a JW Scientific DB 608 capillary column $(30 \mathrm{~m} \times 0.25 \mathrm{~mm} \times 0.25 \mu \mathrm{m})$. Oven temperature was programmed from an initial $80^{\circ} \mathrm{C}$ rising at a rate of $15^{\circ} \mathrm{C} /$ minute to $320^{\circ} \mathrm{C}$. Injector and detector temperatures were $250^{\circ} \mathrm{C}$ and $300^{\circ} \mathrm{C}$ respectively. Carrier gas was $\mathrm{He}$ at a constant flow rate of $2 \mathrm{ml} / \mathrm{min}$ and make-up gas was $\mathrm{Ar}-\mathrm{CH}_{4}$ at $58 \mathrm{ml} / \mathrm{min}$.

\subsubsection{Data Analysis}

Data were analyzed using the SAS system (SAS Institute, Cary, N.C.). Dissipation of bifenthrin was analyzed using
Analysis of Variance (ANOVA) considering 2 soil types and 4 planting ( 3 plant types and 1 no-plant) treatments. Carbon substrate utilization profiling of microbial communities in soil were assessed as absorbances on Biolog Ecoplates after correcting for water. Values of absorbance were plotted against time to provide a qualitative representation of different profiles communities. Principal Component Analysis (PCA) constructed patterns based on different extents of color development on Biolog plates. These patterns were used to relate carbon substrate utilization by microbial communities in the different soil types.

\section{Results and Discussions}

\subsection{Plate Dilution Frequency Assay for Characterizing Bacterial Populations in Soil}

We employed traditional as well as contemporary techniques to provide a clearer picture of the microbial components that involved in rhizodegradation of bifenthrin in soil. The traditional method used was the Plate Dilution Frequency Assay [13] a variation of the Most Probable Number (MPN) for estimating live counts of bacteria in a soil. The contemporary approach involved physiological profiling of microbial communities in soil using carbon substrate utilization patterns (CUPs) also known as the BIOLOG method.

As expected, both soil types contained significantly higher numbers of bacteria when they were planted than when they were bare (Tables 1 and 2). Estimates of bacterial populations after six weeks of incubation in microcosms were $1.0 \times 10^{7}$ bacteria in unplanted Armour soil and $0.2 \times 10^{7}$ bacteria in Sullivan soils.

Enumerations were started at week six when visual observation indicated that soil in the MRS microcosms could be considered as rhizosphere material. At that time, Armour soils planted with AL contained $3.1 \times 10^{7}$ bacteria, increasing to $8.0 \times 10^{7}$ at week 10 before declining to $1.7 \times 10^{7}$ at week 12 (Table 2). Similar patterns of bacterial population dynamics were found in $\mathrm{BB}$ and SG-planted Armour soils. In the former, bacteria popu

Table 2. Plate dilution frequency assay (PDFA) of bacteria in bifenthrin-fortified armour soil.

\begin{tabular}{ccccccc}
\hline \multirow{2}{*}{ System $^{1}$} & \multicolumn{4}{c}{ Numbers of Bacteria at Indicated Period $\left(\times \mathbf{1 0}^{\mathbf{7}}\right)^{\mathbf{2}}$} \\
\cline { 2 - 7 } & \multicolumn{2}{c}{ Week 6} & \multicolumn{2}{c}{ Week 10 } & \multicolumn{2}{c}{ Week 12 } \\
\cline { 2 - 7 } & No & Range & No. & Range & No. & Range \\
\hline NP & $1.0 \mathrm{a}$ & $0.4-2.5$ & $0.4 \mathrm{a}$ & $0.2-1.0$ & $0.1 \mathrm{a}$ & $0.1-0.3$ \\
AL & $3.1 \mathrm{~b}$ & $1.3-7.6$ & $8.0 \mathrm{~b}$ & $3.2-20.0$ & $1.7 \mathrm{~b}$ & $0.7-4.3$ \\
BB & $1.7 \mathrm{~b}$ & $0.7-4.3$ & $4.3 \mathrm{~b}$ & $1.7-11.0$ & $0.4 \mathrm{a}$ & $0.4-1.0$ \\
SG & $0.2 \mathrm{a}$ & $0.1-0.6$ & $2.3 \mathrm{~b}$ & $0.9-5.7$ & $0.4 \mathrm{a}$ & $0.4-1.0$ \\
\hline
\end{tabular}

${ }^{1}$ No plant, NP; alfalfa, AL; big bluestem, BB; switchgrass, $\mathrm{SG} ;{ }^{2}$ Bacterial numbers in a column with same letters are not significantly different; levels of significance and $95 \%$ confidence limits were calculatedas described by Fisher and Yates cited by Harris and Sommers (13). 
lating rose from $1.7 \times 10^{7}$ to $4.3 \times 10^{7}$ before dropping to $0.4 \times 10^{7}$ at week 12 . In SG-planted Armour soils, bacterial numbers at week 6 were $0.2 \times 10^{7}$ increasing over 10 fold to $2.3 \times 10^{7}$ at week 10 before declining to $0.4 \times$ $10^{7}$ at week 12 .

Overall, PDFA estimates of bacteria in planted Sullivan soils showed trends that were similar to those in Armour soils, except in the former soil, bacterial populations under the influence of AL appeared to have reached a higher level sometime before enumeration was performed at week 6 (Table 3). At that time, bacterial populations were $5.9 \times 10^{7}$, but instead of increasing at week 10 as seen in Amour soil, we found a slight decrease to $4.3 \times 10^{7}$. This observation was important; it strongly pointed to growth rate differences between bacterial populations in AL-planted Armour and AL-planted Sullivan soils.

In these studies, we used traditional plate counts for characterizing bacterial components of rhizodegradation in soil. Limitations of plate count methods have been well documented $[15,16]$ nonetheless, these methods remain the 'gold standard' in microbiology, providing relatively inexpensive and well-tested characterization of microbial phenomena in matrices. The PDFA that we used in this study is a relatively simple, resource and time conserving approach to microbial characterization, which provides results that are a function of a dilution series rather one dilution [13]. By its derivation, the PDFA is characteristically associated with wide confidence limits [13] as our results demonstrated. However, important trends such as an apparent difference in growth rate of populations of the two soils were revealed. Accordingly, the PDFA can be valuable in side-by-side comparisons for observations in soils, especially when used together with contemporary approaches such as community profiling [16] and molecular methods [17]

\subsection{Carbon Utilization Profiling of Microbial Communities}

For these studies, we employed carbon substrate profiling (so-called BIOLOG method) as the contemporary approach for characterizing microbial components in the rhizodegradation of bifenthrin in soils. Results of CUP analysis for the major substrate groups, namely carbohydrates (CHOs), amino acids (AAs) and carboxylic acids (CAs) are presented in Figures 1(a)-(f). For brevity, the plots shown are for community profiles in week 10 only. As predicted by PDFA estimates, substrate utilization was higher in all planted soil communities than in unplanted ones. Among Armour rhizosphere soils, $\mathrm{CHO}$ utilization was highest for microbial communities associated with AL; there were no differences in $\mathrm{CHO}$ utilization by communities in SG and BB rhizospheres (Figures 1(a)-(c)). In other words, three microbial communities could be adequately separated based on their $\mathrm{CHO}$ utilization as high (AL), medium (BB and $\mathrm{SG}$ ), and low (NP). Utilization of AAs and CAs was also highest in AL rhizospheres; however, the relative magnitudes of the differences between the substrate utilization these substrates in the rhizospheres or unplanted soil were not as pronounced (Figures 3-5).

Substrate utilization of rhizosphere microbial commu-

Table 3. Plate dilution frequency assay (PDFA) of bacteria in bifenthrin-fortified sullivan soils.

\begin{tabular}{ccccccc}
\hline \multirow{2}{*}{ System $^{1}$} & \multicolumn{4}{c}{ Numbers of Bacteria at Indicated Period $\left(\times \mathbf{1 0}^{\mathbf{7}}\right)^{\mathbf{2}}$} \\
\cline { 2 - 7 } & \multicolumn{3}{c}{ Week 6} & \multicolumn{2}{c}{ Week 10} & \multicolumn{2}{c}{ Week 12} \\
\cline { 2 - 7 } & No. & Range & No. & Range & No. & Range \\
\hline NP & $0.2 \mathrm{a}$ & $0.1-0.4$ & $0.2 \mathrm{a}$ & $0.1-0.6$ & $0.4 \mathrm{a}$ & $0.2-1.0$ \\
$\mathrm{AL}$ & $5.9 \mathrm{~b}$ & $2.4-15.0$ & $4.3 \mathrm{~b}$ & $1.7-11.0$ & $1.7 \mathrm{~b}$ & $0.7-4.3$ \\
$\mathrm{BB}$ & $1.0 \mathrm{~b}$ & $0.4-2.5$ & $4.3 \mathrm{~b}$ & $1.7-11.0$ & $2.3 \mathrm{~b}$ & $0.9-5.7$ \\
$\mathrm{SG}$ & $3.1 \mathrm{~b}$ & $1.3-7.6$ & $4.3 \mathrm{~b}$ & $1.7-11.0$ & $0.4 \mathrm{a}$ & $0.2-1.0$ \\
\hline
\end{tabular}

${ }^{1}$ No plant, NP; alfalfa, AL; big bluestem, BB; switchgrass, SG; ${ }^{2}$ Bacterial numbers in a column with same letters are not significantly different; levels of significance and $95 \%$ confidence limits were calculated as described by Fisher and Yates cited by Harris and Sommers (13)

Table 4. Analysis of variance (ANOVA) of bifenthrin recoveries from two soil types and four planting treatments after 12 weeks.

\begin{tabular}{ccc}
\hline Source of Variation & F & P-value \\
\hline Soil Type & 51.91 & $<0.0001$ \\
Plant Treatment & 28.30 & $<0.0001$ \\
Soil-Plant Interactions & 0.90 & 0.41 \\
\hline
\end{tabular}


Table 5. Dissipation of bifenthrin in unplanted and planted Armour soils.

\begin{tabular}{ccccc}
\hline \multirow{2}{*}{ System1 } & \multicolumn{4}{c}{ \% of Initial Bifenthrin Recovered after Indicated Period } \\
\cline { 2 - 5 } & Week 4 & Week 6 & Week 10 & Week 12 \\
\hline NP & $97.1(10.8) \mathrm{a}$ & $97.1(2.9) \mathrm{a}$ & $112.1(5.4) \mathrm{a}$ & $73.7(0.2) \mathrm{a}$ \\
AL & $80.1(7.1) \mathrm{b}$ & $71.3(8.7) \mathrm{bc}$ & $70.3(17.9) \mathrm{b}$ & $48.7(0.5) \mathrm{c}$ \\
BB & $70.8(1.5) \mathrm{b}$ & $64.1(7.9) \mathrm{c}$ & $67.1(14.4) \mathrm{b}$ & $54.3(0.2) \mathrm{c}$ \\
SG & $76.7(11.3) \mathrm{b}$ & $81.6(14.7) \mathrm{b}$ & $67.8(24.1) \mathrm{b}$ & $64.4(0.2) \mathrm{b}$ \\
\hline
\end{tabular}

1/Mean percentage of initial added bifenthrin recovered after 4, 6, 10 and 12 weeks. Number in parentheses are standard deviations of means of four replicates. Means within a column followed by the same letter are not significantly different at $\alpha=0.05$ level. NP: No Plant; AL: Alfalfa; BB: Big Bluestem; SG: Switchgrass.

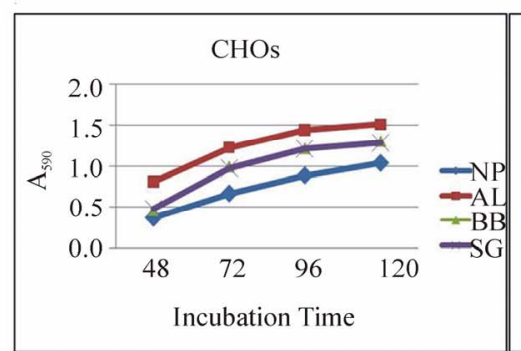

(a)

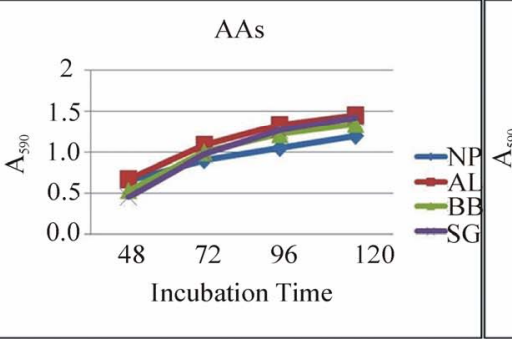

(b)

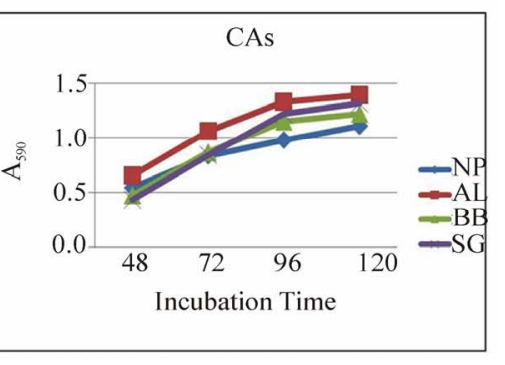

(c)

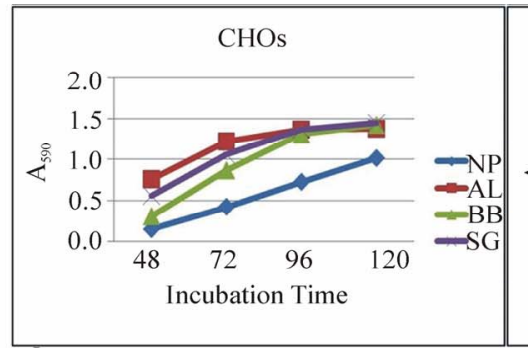

(d)

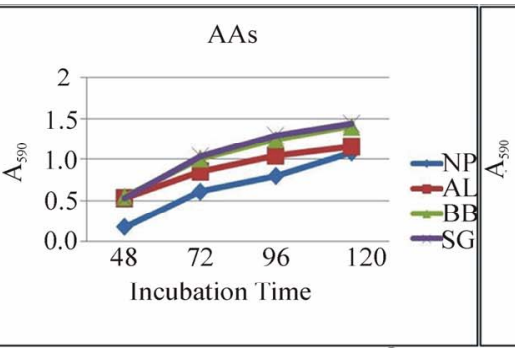

(e)
CAs

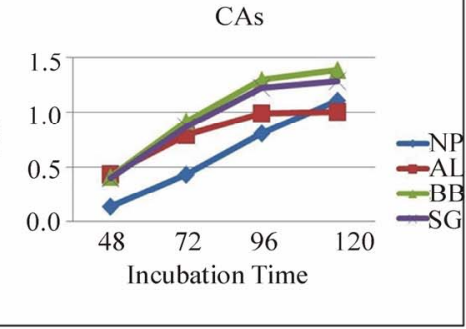

(f)

Figure 1. Qualitative carbon substrate utilization patterns of microbial communities in Armour (a-c) and Sullivan (d-f) soils. CHOs, carbohydrates; AAs, amino acids; CAs, carboxylic acids.

nities in Sullivan soil produced a more mixed pattern than those observed for Armour rhizospheres. In Sullivan soil, utilization of $\mathrm{CHOs}$ was slightly higher in $\mathrm{AL}$ rhizospheres but became undistinguishable as incubation period increased (Figures 1(d)-(f)). Perhaps more remarkably, our PDFA observations reported above were accurately reflected by CUP data.

The Biolog carbon utilization profiling is now widely accepted as by far a more appropriate approach for characterizing microbial populations in a broad range of matrices $(16,18,19)$. However, it is not without its own limitations. Issues of inoculum size and optimum incubation time for different communities are important consideration in the meaningful use of the procedure (19). Perhaps more importantly, the Biolog procedure generates data that is not readily interpretable to provide functionally relevant information.

Currently, the most common approach to Biolog data interpretation for Biolog involves Principal Component
Analysis (PCA), which allows identification of patterns based on differences in color development that might be used to explain observations. PCA analysis of Biolog data from our study is shown in Figure 2. PCA analysis in our study generated three categories: (1) unplanted Armour and Sullivan rhizospheres; (2) the other planting treatments except (3) AL-planted Armour rhizosphere only. There was no difficulty in explaining the clustering together of unplanted soil. Likewise, grouping all planted soils together did not appear to be an aberrant observation; however, we have not found any obvious practical explanation for the distinct separation AL-planted Armor soils. The significance of this observation is undergoing further evaluation.

\subsection{Dissipation of Bifenthrin in Armour and Sullivan Soils}

Comparison of dissipation of bifenthin in Armour and Sullivan soils showed that both soil type and planting 


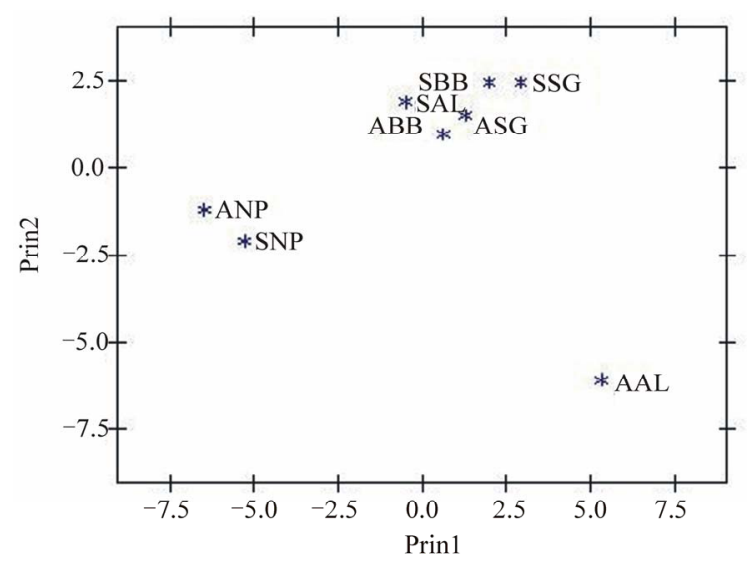

Figure 2. PCA of carbon utilization profiles of microbial communities in bifenthrin-fortified Armour and Sullivan soils at week 10. Soil type: Armour (A); Sullivan (S) Planting system: No plant, NP; alfalfa, AL; big bluestem, BB; switchgrass, SG.

significantly influenced dissipation of bifenthrin in soil (Table 4). There were no soil x plant interactions

Dissipation of bifenthrin in Armour soil is illustrated in Table 5. Beginning in week 4, significantly more bifenthrin was recovered from unplanted soils than in planted ones. After 12 weeks, about $74 \%$ of initially added bifenthrin was recovered in unplanted soil in contrast, $49 \%, 54 \%$ and $64 \%$ of the same initial level was recovered in $\mathrm{AL}, \mathrm{BB}$ and $\mathrm{SG}$ rhizospheres respectively.

Disipation of bifenthrin in Sullivan soil followed a trend similar to one in Armour soil, except the differences between unplanted and planted soils were not manifest in soil samples until week 6, instead week 4 for Armour soil. By week $12,66 \%$ of the initial bifenthrin application were recovered in unplanted Sullivan soil; in contrast, 37\%, $45 \%$ and $36 \%$ respectively in planted soils (Table 6).

\section{Conclusions}

The goal of this study is to understand and characterize the microbial components involved in the rhizodegradation so strategies may be developed to mitigate undesirable intrusions of the xenobiotic compounds in soil and potentially water. We used plate dilution frequency assay (PDFA) and carbon substrate utilization profiling (CUP) to characterize microbial communities in Armour silt loam and Sullivan sandy loam soils that were fortified with the insecticide bifenthrin and planted with alfalfa, big bluestem and switchgrass. Our objective was to determine whether a relationship could be established to relate microbial communities to dissipation of the insecticide in soil. We concluded as follows:

1) Overall, higher microbial populations were found in planted soils than in unplanted ones. Among those planted, Sullivan soils contained higher bacterial popula-
Table 6. Dissipation of bifenthrin in unplanted and planted Sullivan soils.

\begin{tabular}{ccccc}
\hline \multirow{2}{*}{ System1 1} & \multicolumn{3}{c}{ \% of Initial Bifenthrin Recovered after Indicated Period } \\
\cline { 2 - 5 } & Week 4 & Week 6 & Week 10 & Week 12 \\
\hline NP & $69.0(7.1) \mathrm{a}$ & $81.0(1.8) \mathrm{a}$ & $83.5(7.4) \mathrm{a}$ & $66.5(0.4) \mathrm{a}$ \\
AL & $58.1(6.2) \mathrm{a}$ & $51.3(6.2) \mathrm{bc}$ & $59.9(21.0) \mathrm{bc}$ & $36.7(0.5) \mathrm{b}$ \\
BB & $67.7(4.4) \mathrm{a}$ & $59.7(6.9) \mathrm{b}$ & $41.2(9.4) \mathrm{c}$ & $45.4(0.6) \mathrm{b}$ \\
SG & $68.5(7.4) \mathrm{a}$ & $47.2(8.5) \mathrm{c}$ & $62.3(7.0) \mathrm{b}$ & $36.0(0.6) \mathrm{b}$ \\
\hline
\end{tabular}

1/Mean percentage of initial added bifenthrin recovered after 4, 6, 10 and 12 weeks. Number in parentheses are standard deviations of means of four replicates. Means within a column followed by the same letter are not significantly different at $\alpha=0.05$ level. NP: No Plant; AL: Alfalfa; BB: Big Bluestem; SG: Switchgrass.

tions than Armor soils. Furthermore, the highest populations of bacteria were found in both soil types when they were planted with alfalfa.

2) Carbon utilization profiles measured by the Biolog procedure for carbohydrates, amino acids and carboxylic acids were higher in planted soils than unplanted. CUP was accurately reflected by bacterial populations in soil; additionally, it suggested differences in growth rate of microbial communities in two soils.

3) Principal Component Analysis (PCA) separated CUP data into three group namely, unplanted soils, alfalfa-planted Armour soils, and all other planting treatments. The significance of this observation is not immediately obvious.

4) As expected, significantly more bifenthrin was recovered in both unplanted Armour and Sullivan soils than in planted ones. Furthermore, dissipation of bifenthrin was generally higher in Sullivan than in Armour soils.

5) We are evaluating microbiological data vis-à-vis bifenthrin dissipation to establish a relationship, which could be a major step toward identification of major individuals or consortia of microorganisms that are most important in the dissipation of bifenthrin in soil.

\section{REFERENCES}

[1] R. L. Chaney, J. S. Angle, C. L. Broadhurst, C. A. Peters, R. V. Tappero and D. L. Sparks, "Improved Understanding of Hyperaccumulation Yields Commercial Phytoextraction and Phytomining Technologies," Journal of Environmental Quality, Vol. 36, 2007, pp. 1429-1443. doi:10.2134/jeq2006.0514

[2] J. I. Schnoor, L. A. Light, S. C. McCutcheon, N. L. Wolfe and L. H.Carreira, "Phytoremediation of Organic and Nutrient Contaminants. Pilot and Full-Scale Studies are Demonstrating the Promise and limitations of Using Vegetation for Remediating Hazardous Wastes in Soils and Sediments," Environmental Science \& Technology, Vol. 29, No. 7, 1995, pp. 318-323. doi:10.1021/es00007a002 
[3] R. L. Schneider and D. D. Yifru, "Phytoremediation of Perchlorate from Fireworks," 11th International Symposium on Fireworks, Puerto Vallarta, April 20-24, 2009, pp. 387-396.

[4] A. Muratova, T. Hübner, S. Tischer, O. Turkovskaya, M. Möder and P. Kuschk, "Plant-Rhizosphere-Microflora Association during Phytoremediation of PAH-Contaminated Soil," International Journal of Phytoremediation, Vol. 5, No. 2, 2003, pp. 137-151. doi:10.1080/713610176

[5] J. M. Duringer, A. M. Craig, D. J. Smith and R. L. Chaney, "Uptake and Transformation of Soil [14C]-Trinitrotoluene by Cold-Season Grasses," Environmental Science \& Technology (ACS Publications), Vol. 44, No. 16, 2010, pp. 6325-6330. doi:10.1021/es903671n

[6] E. K. Dzantor, J. E. Woolston and B. Momen, "PCB Dissipation and Microbial Community Analysis in Rhizosphere Soil under Substrate Amendment Conditions," International Journal of Phytoremediation, Vol. 4, No. 4, 2002, pp. 283-295. doi:10.1080/15226510208500088

[7] A. A. Romeh, "Phytoremediation of Water and Soil Contaminated with Imidacloprid Pesticide by Plantago Major L," International Journal of Phytoremediation, Vol. 12, No. 2, 2010, pp. 188-199. doi:10.1080/15226510903213936

[8] J. Gan, S. J. Lee, W. P. Liu, D. L. Haver and J. N. Kabashima, "Distribution and Persistence of Pyrethroids in Runoff Sediments," Journal of Environmental Quality, Vol. 34, 2005, pp. 836-841. doi:10.2134/jeq2004.0240

[9] National Plant Board, U.S. Dosmetic Japanese Beetle Harmonization Plan, 2004.

[10] A. Fecko, "Environmental Fate of Bifenthrin," Environmental Monitoring and Pest Management Branch, Department of Pesticide Regulation, Sacramento, 1999.

[11] E. K. Dzantor, D. E. Long and T. K. Amenyenu, "Use of Plant System for Mitigating Environmental Impacts of
Pesticides," Proceeding of the Southern Nurserymen Association Annual Conference, Atlanta, 2005, pp. 580-583.

[12] E. K. Dzantor and J. E. Woolston, "Enhancing Dissipation of Aroclor 1248 (PCB) Using Substrate Amendment in Rhizosphere Soil," Journal of Engineering \& Environmental Sciences, Vol. 36, No. 1, 2001, pp. 1861-1871.

[13] R. F. Harris and L. E. Sommers, "Plate-Dilution Frequency Technique for Assay of Microbial Ecology," Applied Microbiology, Vol. 16, No. 2, 1968, pp. 330-334.

[14] V. J. Orphan, L. T. Taylor, D. Hafenbradl and E. F. Delong, "Culture-Dependent and Culture Independent Characterization of Microbial Assemblages Associated with High Temperature Petroleum Reservoirs," Applied and Environmental of Microbiology, Vol. 66, No. 2, pp. 700-711. doi:10.1128/AEM.66.2.700-711.2000

[15] E. Yashiro, R. N. Spear and P. S. McManus, "Culture-dependent and Culture-Independent Assessment of Bacteria in the Apple Phyllosphere," Journal of Applied Microbiology, Vol. 110, No. 5, 2010, pp. 1284-1296. doi:10.1111/j.1365-2672.2011.04975.x

[16] J. L. Garland and A. L. Mills, "Classification and Characterization of Heterotrophic Microbial Communities on the basis of patterns of Community-Level Sole-Carbon-Source Utilization," Applied and Environmental Microbiology, Vol. 57, No. 8, 1991, pp. 2351-2359.

[17] V. Torsvik, J. Goksoyr, and F. L. Daae, "High Diversity in DNA of Soil Bacteria," Applied and Environmental Microbiology, Vol. 56, No. 3, 1991, pp. 782-787.

[18] K. Matsui, M. Jun, M. Ueki and Z. I. Kawabata, "Functional Succession of Bacterioplankton on the Basis of Carbon Source Utilization Ability by Biolog Plates," Ecological Research, Vol. 16, No. 5, 2003, pp. 905-912.

[19] A. Stefanowicz, "The Biolog Plates Technique asa Tool in Ecological Studies of Microbial Communities," Polish Journal of Environmental Studies, Vol. 15, No. 5, 2006, pp. 669-676. 